\title{
Beyond Obesity: The Diagnosis and Pathophysiology of Metabolic Syndrome
}

\author{
WAYNE GADE, JESSICA SCHMIT, MELISSA COLLINS, JEAN GADE
}

\section{LEARNING OBJECTIVES}

After reading the following article, the reader will be able to answer the following:

1. Identify the major contribution to our understanding of obesity and metabolic syndrome by each of the following researchers: Gerald Reaven, Norman Kaplan, Richard Unger, and Jeffery Friedman.

2. Identify the criteria used for diagnosis of metabolic syndrome (MSX).

2. Identify and describe three outcomes of normal leptin feedback to hypothalamus and three outcomes related to leptin resistance.

3. Describe the relationship between free fatty acids (FFAs) and ceramide and their significance in lipotoxicity and apoptosis.

4. Describe four destructive outcomes of elevated FFAs leading to disease and apoptosis.

5. Identify a proposed physiologic role for leptin that is independent of hypothalamus.

6. List four differences between metabolically healthy obese individuals and those with metabolic syndrome.

\footnotetext{
The Focus section seeks to publish relevant and timely continuing education for clinical laboratory practitioners. Section editors, topics, and authors are selected in advance to cover current areas of interest in each discipline. Readers can obtain continuing education credit (CE) through P.A.C.E. ${ }^{\circ}$ by completing the continuing education registration form, recording answers to the examination, and mailing a photocopy of it with the appropriate fee to the address designated on the form. Suggestions for future Focus topics and authors, and manuscripts appropriate for $C E$ credit are encouraged. Direct all inquiries to the Clin Lab Sci Editorial Office, Westminster Publishers, 315 Westminster Court, Brandon MS 39047. (601) 214-5028, (202) 315-5843 (fax).westminsterpublishers@comcast.net.
}

7. Describe "lipid buffering" and how the development of leptin resistance allows fat deposition into nonadipocytes (ectopic fat).

8. Describe why glyceroneogenesis and PEPCK activity are required for "lipid buffering" or fatty acid re-esterification.

9. Describe the signal transduction resulting from leptin binding (JAK/STATsystem), which exerts both transcriptional level control (PPARs) and control of pre-existing enzyme activities through the AMPK system.

10. Discuss the importance of adiponectin (ADN) as an "adipokine" in relation to obesity and metabolic syndrome.

11. Describe the development of atherosclerosis including the inflammatory process that recruits macrophages and list three ways that $\mathrm{ADN}$ helps prevent this process.

\section{Clin Lab Sci 2010;23(1);51}

Wayne Gade, PhD, MT(ASCP), Associate Professor, Clinical Lab Science Program, University of Illinois Springfield, Springfield, IL

Jean Gade, MS, BS(RN), Nurse Educator, Lincoln Prairie Behavioral Health, Springfield, IL.

\section{Melissa Collins, MLS (ASCP), Medical Lab Scientist, Skokie Hospital, 9600 Gross Point Rd, Skokie, IL.}

Jessica Schmit, Student, Clinical Lab Science Program, University of Illinois Springfield, Springfield, IL.

Address for Correspondence: Wayne Gade, Clinical Laboratory Science \& Chemistry Departments, HSB Rm 314, One University Place, Springfield, IL 62703, wgade1@uis.edu, 217-725-6384. 


\section{FOCUS: OBESITY AND METABOLIC SYNDROME}

\section{ABSTRACT}

Metabolic syndrome (MSX) identifies clinical symptoms and lab results, including abdominal obesity, insulin resistance, hyperglycemia, hyperlipidemia, and hypertension, that lead to an increased risk of cardiovascular disease (CVD). Obesity typically results in insulin and leptin resistance and a shift from expansion of subcutaneous fat to deposition of abdominal and ectopic fat. These conditions cause metabolic dysregulation, elevated fatty acids (FFA), and increased secretion of pro-inflammatory "adipokines". Left untreated, these conditions cause lipotoxicity, chronic inflammation, hypertension, atherosclerosis, and CVD.

\section{INTRODUCTION}

Abdominal obesity is the most obvious symptom of metabolic syndrome, the term used to describe a cluster of symptoms that increase risk of cardiovascular disease (CVD). In 1988, Reaven's landmark paper included type 2 diabetes (DM2), insulin resistance, hyperglycemia, hyperlipidemia, and hypertension as risk factors for atherosclerosis and CVD. ${ }^{1,2}$ A year later, Kaplan included abdominal obesity, glucose intolerance, hypertension, and hyperlipidemia as the "deadly quartet," thereby formalizing the connection between obesity, metabolic syndrome, and cardiovascular risk. ${ }^{3}$ Thousands of papers have discussed various aspects of the syndrome and proposed many names. Metabolic syndrome is the regrettably generic term used most often. ${ }^{4-11}$

Other medical conditions associated with obesity include DM2, several forms of cancer, renal and liver diseases, polycystic ovarian syndrome, sleep apnea, chronic inflammation, and atherosclerosis. ${ }^{4-14}$ In 1983 , researchers reported that women with visceral (android) fat were 10-fold more likely to develop diabetes than women with similar amounts of lower body (gynoid) fat. ${ }^{15}$ Leptin, a hormone secreted by fat cells, directs storage of excess calories into subcutaneous deposits, but as obese patients develop leptin resistance, fat is deposited between visceral organs and inside nonadipocytes (ectopic fat). ${ }^{9}, 10-13$ Visceral adipose tissue (VAT) consists of larger cells with increased lipolysis (releasing FFAs) and greater secretion of pro- inflammatory factors than subcutaneous adipocyte tissues. ${ }^{9,10-13}$

Enzyme or hormone deficiencies cause many metabolic diseases, such as type I diabetes, phenylketonuria (PKU), or von Gierke's disease (impaired glycogen storage). ${ }^{16}$ Genetic analysis from family and twin studies of obesity produces estimates of "heritability" ranging from $30-70 \%$, meaning that approximately half of the variation in body mass within a population is a result of inherited factors. ${ }^{17-20}$ Most experts assume a polygenic component to obesity and that individual "obesity genes" typically make only modest contributions toward a person's BMI. ${ }^{17,} 19,20$

In most cases, the underlying cause of MSX is acquired hormone resistance caused by "overnutrition" that overwhelms previously normal endocrine function. ${ }^{4,5}$ Leptin resistance releases appetite suppression, decreases caloric expenditure, and permits storage of excess calories as VAT. Abdominal fat and hormonal resistances lead to dysfunctional lipid and carbohydrate metabolism, lipotoxicity, and apoptosis (programmed cell death). ${ }^{9-12}$ Chronic inflammation is promoted by excessive secretion of "adipokines" (cytokines secreted by fat cells) that lead to "hyperresponsiveness" of the arterial endothelium, increased leukocyte recruitment, oxidative damage, plaque formation, hypertension,

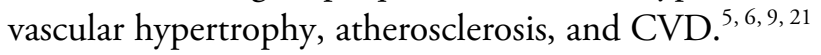

Physiological connections between the diverse symptoms were initially unclear, but molecular explanations are resolving the complex relationships and bringing many causes of heart disease into sharper focus. Researchers recognize that many factors contribute to obesity, including genetics, stress, poor lifestyle habits, compulsive or depressive disorders, and many more. The preceding article discusses hormonal feedback systems that originally curb appetite, increase metabolism and promote physical activity to prevent rapid weight gain. ${ }^{22}$ However hormonal resistance occurs, development of obesity becomes more likely. This review focuses on the consequences of obesity, including metabolic syndrome and cardiovascular disease. 


\section{Diagnostic Criteria for Metabolic Syndrome}

Many organizations worldwide have proposed diagnostic criteria for MSX; Table 1 summarizes criteria from three prominent organizations, the World Health Organization (WHO), the National Cholesterol Education Program (NCEP, also known as the Adult Treatment Panel III), and the American Association of Clinical Endocrinologists (AACE). ${ }^{5}$ A 1998 WHO report defined MSX assuming insulin resistance and hyperglycemia, along with two or more of the following: obesity (high waist to hip ratio or BMI > 30), a poor lipid profile with high TGs and low HDLs, hypertension, and renal damage (indicated by microalbuminuria). ${ }^{14}$

Both NCEP and AACE criteria specifically excluded diabetic patients (as a separate diagnosis), but assumed insulin resistance and the "pre-diabetic" hyperglycemic conditions of impaired fasting glucose (IFG) and/or impaired glucose tolerance (IGT), along with hyperlipidemia, high cholesterol, hypertension, and abdominal obesity. ${ }^{5,23}$ The NCEP and AACE criteria are typically used by physicians for diagnosis of MSX (designated dysmetabolic syndrome X, ICD-9 diagnostic code 277.7). The AACE criteria also include a family history of CVD, diabetes, or hypertension. ${ }^{5,23}$

Note that all definitions combine easy physical measurements (estimates of BMI, waist to hip ratios, etc) with routine lab analyses, such as elevated glucose, TGs, total cholesterol, HDLs and LDLs. Thus, diagnosis of MSX is possible in the absence of obesity if non-obese patients have dyslipidemia, hyperglycemia, and hypertension (see Table 1). Although measurements of hormones such as insulin, cortisol, and leptin would help define underlying abnormalities, they would require complex and expensive lab measurements that are not required for the diagnosis. The diagnostic goal is to identify patients with increased cardiovascular risk. 14,23

\section{Pathophysiology of Metabolic Syndrome}

Human obesity is far more often related to "overnutrition" and resistances to insulin, leptin and cortisol than to genetic deficiencies. ${ }^{5-8,17-20,24,25}$ The accompanying article acknowledges many different causes of weight gain and describes leptin and insulin resistances as landmarks along the "highway to obesity". 22 The present article continues along the obesity highway toward the MSX pathologies of lipotoxicity, apoptosis, chronic inflammation, hypertension, atherosclerosis, and CVD.

\section{Cortisol Promotes Appetite and Abdominal Fat}

Various forms of stress cause the hypothalamus to signal the pituitary to release adrenocorticotrophic hormone (ACTH), which stimulates the adrenal cortex to release cortisol. ${ }^{16}$ Cortisol, a steroid hormonal, alters metabolism and also stimulates an appetite for high calorie "comfort" foods and deposition of abdominal fat. ${ }^{16,24,25}$ Cortisol helps redistribute energy reserves by promoting release of amino acids from protein catabolism and gluconeogenesis and lipid synthesis. ${ }^{16}$ Glucocorticoid hormone levels vary widely in a diurnal pattern, respond to environmental influences, and exist as both an inactive (cortisone) and active (cortisol) form in plasma. Interconversion between these forms by the enzyme 11$\beta$-hydroxysteroid dehydrogenase type I (11- HSD) is tissue-specific and is the subject of intense research. ${ }^{24,25}$

\section{Leptin Helps Restrict Abdominal Fat Deposition}

Leptin levels initially increase with increasing fat cell mass and provide feedback to the hypothalamus of adequate "adiposity" or energy reserves. The hypothalamus then suppresses appetite, stimulates physical activity, and promotes thermogenesis to utilize excess calories. $^{5-7}$ Therefore, leptin plays a critical role in directing fat deposition and control of body weight. ${ }^{27,28}$

Leptin normally directs deposition of fat to preexisting subcutaneous fat cells, while restricting ectopic TG deposition and expansion of deposition within VAT. ${ }^{9}$ 11-13, 26-30 Rapid or excessive weight gain leads to dyslipidemia and leptin resistance, causing the hypothalamus to become unresponsive, no longer suppressing hyperphagia. ${ }^{11-13,27,28}$ Infusion of leptin into leptindeficient animals corrects diet-induced steatosis and dyslipidemia $^{31}$. 


\begin{tabular}{|c|c|c|c|}
\hline Symptom & WHO & NCPE (ATP III) & AACE \\
\hline Hyperglycemia & $\begin{array}{l}\text { IFG or DM2 as } \\
\text { initiating factor }\end{array}$ & IFG $(\mathrm{FG}>110 \mathrm{mg} / \mathrm{dL})$ & $\begin{array}{l}\text { IFG }(\text { FG }>110-125 \mathrm{mg} / \mathrm{dL}) \\
2 \mathrm{hr} \text { OGTT glucose level } \\
>140 \mathrm{mg} / \mathrm{dL}\end{array}$ \\
\hline Insulin resistance & $\begin{array}{l}\text { DM2 is considered } \\
\text { the "initiating" factor }\end{array}$ & $\begin{array}{l}\text { IFG, insulin resistance } \\
\text { is assumed, but DM2 not } \\
\text { included in definition }\end{array}$ & $\begin{array}{l}\text { IFG or IGT, Insulin resistance is, } \\
\text { assumed but DM2 is not included }\end{array}$ \\
\hline Abdominal Obesity & $\begin{array}{l}\text { Waist to hip ratio } \\
0.90 \text { in } \delta ;>0.85 \text { in } q \\
\text { or } \mathrm{BMI}>30 \mathrm{~kg} / \mathrm{m}^{2}\end{array}$ & $\begin{array}{l}\text { Waist circumference: } \\
\text { > } 40 \text { in. } \widehat{~} \text {; > } 35 \mathrm{in} .+9\end{array}$ & $\begin{array}{l}\mathrm{BMI}>25 \mathrm{~kg} / \mathrm{m}^{2} \text { or waist: } \\
\text { circumference }>40 \text { in. } \widehat{\delta} \text {; } \\
>35 \mathrm{in} .+9\end{array}$ \\
\hline Hypertriglyceridemia & TGs $>150 \mathrm{mg} / \mathrm{dL}$ & TGs $>150 \mathrm{mg} / \mathrm{dL}$ & TGs: $\geq 150 \mathrm{mg} / \mathrm{dL}$ \\
\hline $\begin{array}{l}\text { Hypercholesterolemia } \\
\text { (with decreased HDL) }\end{array}$ & $\begin{array}{l}\mathrm{HDL}<35 \mathrm{mg} / \mathrm{dL} \sigma^{\lambda} \\
\mathrm{HDL}<39 \mathrm{mg} / \mathrm{dL} q\end{array}$ & $\begin{array}{l}\mathrm{HDL}<40 \mathrm{mg} / \mathrm{dL} \sigma^{\Uparrow} \\
\mathrm{HDL}<50 \mathrm{mg} / \mathrm{dL} q\end{array}$ & $\begin{array}{l}\mathrm{HDL}<40 \mathrm{mg} / \mathrm{dL} \hat{\sigma} \\
\mathrm{HDL}<50 \mathrm{mg} / \mathrm{dL} \phi\end{array}$ \\
\hline Hypertension & $>140 / 90 \mathrm{~mm} \mathrm{Hg}$ & $>130 / 85 \mathrm{~mm} \mathrm{Hg}$ & $>130 / 85 \mathrm{~mm} \mathrm{Hg}$ \\
\hline $\begin{array}{l}\text { Other factors: family } \\
\text { history,age, sex, } \\
\text { ethnicity,proteinuria }\end{array}$ & $\begin{array}{l}>20 \mu \mathrm{g} / \mathrm{min} \text { microalbumin } \\
\text { or albumin/creatinine } \\
>20 \mathrm{mg} / \mathrm{g}\end{array}$ & Not included in definition & $\begin{array}{l}\text { Sedentary lifestyle, age, ethnicity, } \\
\text { family history }\end{array}$ \\
\hline $\begin{array}{l}\text { Diagnostic } \\
\text { Requirements }\end{array}$ & $\begin{array}{l}\text { Diabetes, IGT, IFG, or IRS } \\
\text { and two or more of above }\end{array}$ & $\begin{array}{l}\text { Three or more of the } \\
\text { above factors included }\end{array}$ & $\begin{array}{l}\text { Insulin resistance assumed but } \\
\text { seldom measured. Final diagnosis is } \\
\text { left to discretion of physician }\end{array}$ \\
\hline
\end{tabular}

As seen in Figure 1A, leptin binding to a non-adipose cell, activates a signaling pathway (designated JAK/ STAT) that produces a transcription factor (designated PPAR- $\alpha$ ), which promotes transcription of genes needed for $\beta$-oxidation of FFAs. However, in fat cells, TG storage is promoted over $\beta$-oxidation (not shown). Diet-induced obesity (DIO) leads to leptin resistance and a different transcription factor (designated PPAR- $\gamma$ ) promotes enzymes involved with lipid synthesis and storage. Since the cells depicted in Figure 1B are nonadipose cells, storage of significant amounts of TGs would constitute ectopic fat deposition. Unfortunately one outcome of the excessive FA synthesis is the production of the lipotoxic compound ceramide.

\section{VAT Releases More FFAs}

Three different lipase enzymes release free fatty acids (FFAs) and glycerol ${ }^{16}$ from dietary TGs (pancreatic lipase), TGs transported in lipoproteins (lipoprotein lipase, LPL), or TGs stored in adipocytes (hormone sensitive lipase, HSL).

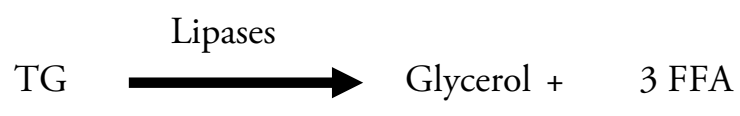

Larger abdominal adipocytes exhibit higher HSL activity than smaller subcutaneous fat cells, releasing more levels of FFAs directly into the portal circulation of the liver. ${ }^{9 .}{ }^{11-13,28}$ Increased FFAs have profound effects on liver metabolism and are lipotoxic to many tissues. ${ }^{911-13}$

\section{Ectopic Fat and VAT Are Relatively Toxic}

Leptin resistance "allows" ectopic fat deposition in liver, heart, pancreas, and muscle tissues. ${ }^{13} \mathrm{~A}$ major consequence of VAT and ectopic fat is the increased release of FFA into the serum. In addition to increased 


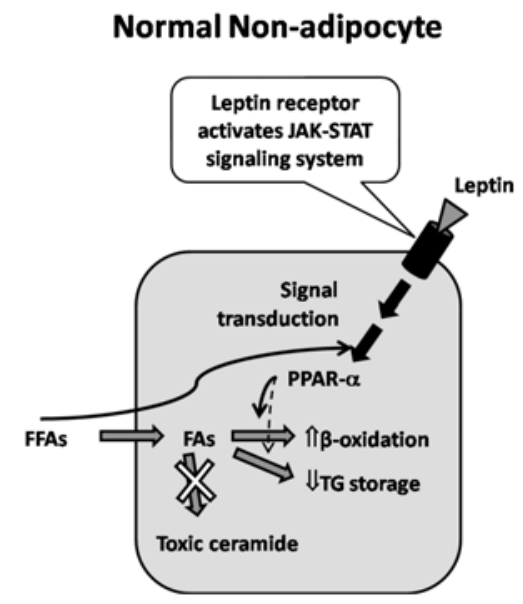

A. Normal non-adipocytes respond to leptin by activating the signaling pathways and producing the transcription element designated PPAR- $\alpha$ (peroxisome proliferatoractivated receptor- $\alpha$ ). The element promotes $\beta$-oxidation (solid line) and decreases triglyceride storage (TG, dashed line).

\section{Leptin Resistant Non-adipocyte}

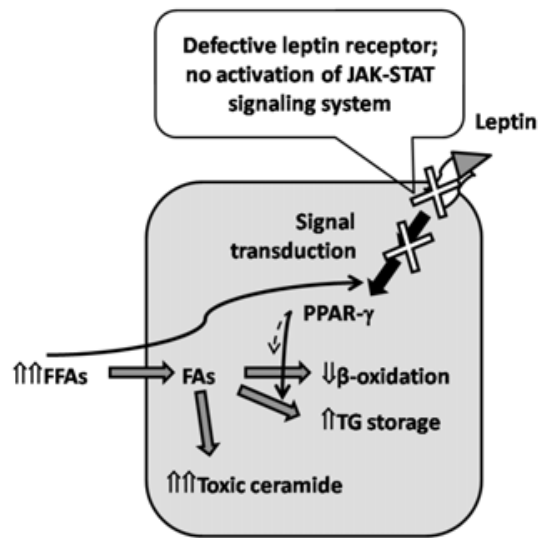

B. Leptin resistant non-adipocytes do not respond to leptin and a different transcription element designated PPAR- $\nu$ (peroxisome proliferator-activated receptor- $\gamma$ ) is produced. This element promotes TG storage (solid line) and decreases $\beta$-oxidation (dashed line). Elevated free fatty acids(FFAs), are often seen in leptin resistance and are also combined with the amino acid serine to form cytotoxic ceramide.

Figure 1: Toxic Effects of FFAs and Leptin Signaling in Non-Adipocytes

lipolysis, abdominal fat secretes more adipokines, such as $\alpha$-TNF, IL-6, and CRP, which promote inflammation, oxidative damage, and atherosclerosis. 5,9 , $11,21,32,32$

Fatty liver, frequently associated with MSX, is often differentiated into alcoholic and non-alcoholic steatosis. $^{29,30}$ Normal hepatic metabolism supplies fasting glucose and secretes the majority of plasma proteins, including albumin, lipoproteins, and coagulation factors. Fatty liver disorders reduce protein secretion, leading to clotting disorders, dyslipidemia, and edema. ${ }^{29,30}$ Alcoholic fatty liver results from ethanol's high caloric content, disrupted glucose metabolism, and ethanol's easy conversion to fatty acids. Nonalcoholic steatohepatitis (NASH) is very common among obese patients and is now recognized as the most common cause of elevated liver enzymes among asymptomatic patients. ${ }^{9,29,30}$ Exposure of cultured hepatocytes to high levels of FFAs resulted in uncontrolled gluconeogenesis and excessive export of glucose. ${ }^{31} \mathrm{NASH}$ results in elevated AST and ALT levels, hyperlipidemia, decreased secretion of plasma proteins, and altered hepatic metabolism. ${ }^{9,29-32}$ Ectopic fat results in increased secretion of pro-inflammatory adipokines, hepatomegaly, and hepatocellular damage caused by toxic ceramide, apoptosis, and replacement of hepatocytes with fibroblasts. ${ }^{9} 29-33$

Ectopic fat deposited within the pancreas results in a similar dysfunction, as illustrated in Figure 2. ${ }^{13}$ Hypersecretion of insulin initially coincides with TG deposition in pancreatic tissue, but, eventually, lipotoxic cell damage decreases insulin secretion and causes insulinopenia similar to that seen in DM1. ${ }^{13}$ Cultured $\beta$-cells exposed to chronic high FFA levels secrete less insulin ${ }^{9,11-13}$. These changes result in decreased glucose uptake and increased gluconeogenesis, observed in IFG, IGT, and DM2. ${ }^{9,13,32}$

Ventricular hypertrophy often results from leptin resistance and ectopic fat deposition within myocardial tissue. ${ }^{11,34}$ Again, lipotoxicity and chronic inflammatory conditions promote cellular damage, inefficient contractions, and dysfunctions such as hypertension and congestive heart failure. ${ }^{9,11,34}$ 


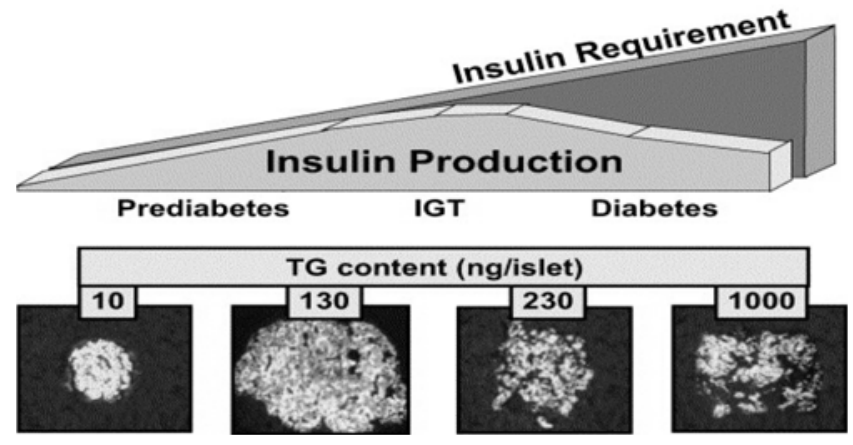

Figure 2: Pancreatic Fat Deposition Related to Insulin Production $\&$ Resistance. Insulin production peaks during the prediabetic or glucose intolerance (IGT) phases (shown by stained cell masses), then decreases as islets undergo lipotoxicity. Pancreatic cells undergo ectopic fat deposision, indicated by TG content increases from 10 to $1000 \mathrm{ng} /$ islet. Insulin requirements continue to increase as other tissues become more resistant. Some DM2 patients essentially convert to DM1 as ectopic fat and lipotoxicity destroys pancreatic function. (with permission from Unger RH, Biochimie 2005; 87: 57-64).

In skeletal muscle, fatty deposits decrease the efficiency of contractions, adding resistance to cardiovascular function and hypertension. ${ }^{\text {? }}$

Although abdominal obesity is not an absolute prerequisite for diagnosis of MSX, ectopic fat is extremely common and correlates with increased risk of CVD. However, as figure 3 illustrates, obese patients with less abdominal fat have better metabolic profiles and healthier outcomes than patients with similar BMIs, but more abdominal obesity.

\section{Metabolic Changes and Hormone Resistances}

Insulin promotes glucose uptake by muscle and fat cells and the storage of carbohydrates (as glycogen), lipids (as TGs) and amino acids (as proteins), while inhibiting glycogenolysis, lipolysis, and protein catabolism ${ }^{16}$. Insulin resistance diminishes these functions, leading to dysregulation of carbohydrate and lipid metabolism. As a result, obese patients with DM2 and MSX typically exhibit hyperglycemia and elevated FFAs, TGs, and total and LDL cholesterol (See Table 2). ${ }^{4-13}$

Phosphoenolpyruvatecarboxykinase (PEPCK) as key enzyme in the dysregulation of lipid and glucose metabolism." 911,12 PEPCK catalyzes the "first committed
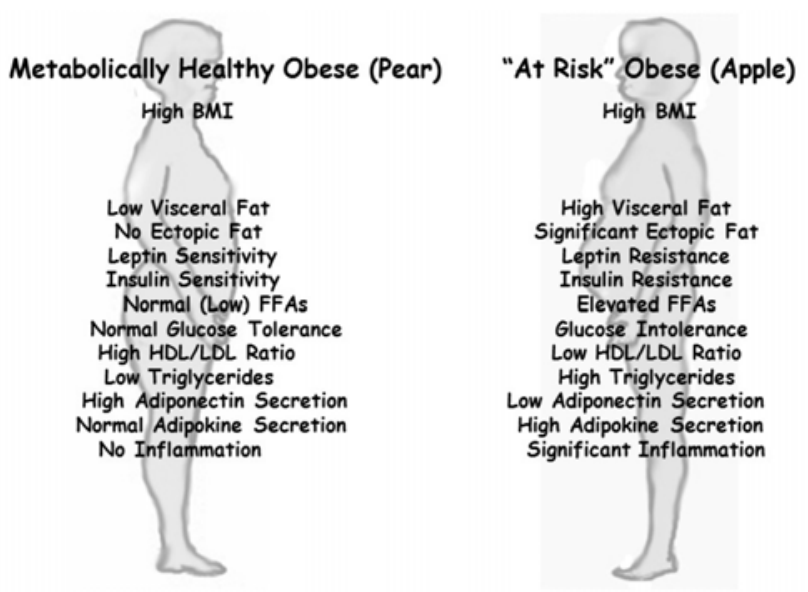

Figure 3: Comparison of Subcutaneous Fat (Pears) \& Visceral Fat (Apples) High BMIs associated with predominantly visceral fat deposition (often called "apple shaped") are related to numerous physiologic changes that are detrimental to the patient. Patients with similar BMIs, but lesser amounts of visceral fat (often referred to as pears) are more "metabolically healthy" and suffer fewer of the effects of metabolic syndrome.

ed step" of both gluconeogenesis and glycerolneogenesis (synthesis of glycerol for use in TGs). ${ }^{16}$ The reaction below shows a simultaneous decarboxylation and phosphorylation of oxaloacetic acid and to form phosphoenolpyruvate.

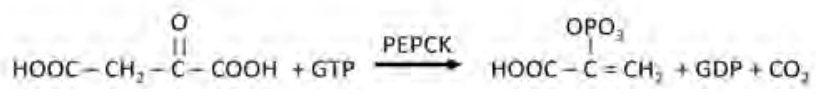

As described in the previous article, glyceroneogenesis is critical to "lipid buffering", involving lipolysis, followed by re-esterification back to TGs, all within the same cell. Overexpression of PEPCK leads to obesity in rabbits on a normal diet. However, because of effective lipid buffering, the obesity occurs without significant ectopic fat deposition, insulin or leptin resistance, or excessive release of FFAs. ${ }^{35}$ On a high fat diet, however, these animals deposit ectopic fat, develop insulin resistance, and metabolic dysregulation ${ }^{35}$. When excess dietary lipids are available, lipid buffering is overwhelmed and the excess calories accumulate within non-adipose tissues.

AMPK, Transcription, and Obesity Metabolism Leptin provides feedback of energy status through the 
FOCUS: OBESITY AND METABOLIC SYNDROME

\author{
Table 2: Typical Clinical Data* for Patients With and Without \\ Metabolic
}

$\begin{array}{lccr}\text { Clinical Analyte } & \begin{array}{c}\text { Obese Non-MSX } \\ \text { Patient Data }\end{array} & \begin{array}{c}\text { Obese MSX } \\ \text { Patient Data }\end{array} & \begin{array}{r}\text { Reference Range } \\ \text { or Limits }\end{array} \\ \text { Fasting glucose } & 5.3 & 6.0 & <6.1 \mathrm{mmol} / \mathrm{L} \\ 2 \text { hr glucose OGTT } & 6.9 & 13.9 & <11.1 \mathrm{mmol} / \mathrm{L} \\ \text { Triglycerides } & 1.4 & 3.2 & 0.6-3.7 \mathrm{mmol} / \mathrm{L} \\ \text { Total cholesterol } & 4.9 & 6.5 & <5.2 \mathrm{mmol} / \mathrm{L} \\ \text { HDL-cholesterol } & 1.5 & 1.1 & 0.7-1.7 \mathrm{mmol} / \mathrm{L} \\ \text { LDL-cholesterol } & 3.5 & 5.0 & 2.2-5.0 \mathrm{mmol} / \mathrm{L} \\ \text { Free fatty acids } & 0.5 & 0.6 & 0.3-0.9 \mathrm{mmol} / \mathrm{L} \\ \text { Fasting insulin } & 57 & 168 & <120 \mathrm{pmol} / \mathrm{L} \\ \text { Insulin resistance** } & 3.6 & 7.7 & \\ \text { Leptin } & 3.11 & 2.96 & \mu . / \mathrm{L} \\ \text { Adiponectin } & 10.4 & 7.6 & 8.0-12.0 \mathrm{mg} / \mathrm{L} \\ \text { hs-CRP } & 4.4 & 5.0 & 0.2-6.1 \mathrm{mg} / \mathrm{L} \\ \text { TNF- } \alpha & 2.8 & 3.3 & 2.0-3.1 \mu \mathrm{\mu g} / \mathrm{L}\end{array}$

* Data obtained from Xydakis, A.M., Case, C.C., Jones, P.H. and others. Adiponectin, Inflammation, and Expression of the Metabolic Syndrome in Obese Individuals: The Impact of Rapid Weight Loss through Caloric Restriction. J. Clin. Endocrin. 2004; 89 (6): 2697-03 and Tietz' Fundamentals of Clinical Chemistry, $6^{\text {th }}$ Edition (Ref \# 53)

** Insulin resistance calculated from HOMA (homeostasis model assessment $(\mathrm{IR}=$ fasting glucose $(\mathrm{mg} / \mathrm{dL}) \times$ fasting insulin $(\mu \mathrm{U} / \mathrm{mL}) /$ 22.5)

AMP-activated protein kinase (AMPK) phosphorylation system. The AMPK system integrates this extracellular information with the intracellular energy status, via the AMP:ATP ratio. ${ }^{35,36}$ Leptin binding to hypothalamic receptors communicates, through the AMPK system, that energy status is adequate and signals for appetite control, thermogenesis, and increased activity. ${ }^{35,}{ }^{36} \mathrm{In}$ liver and muscle, leptin binding activates AMPK, thereby stimulating $\beta$-oxidation of fatty acids and inhibiting synthesis of TG and FA. This restricts ectopic fat deposition in these tissues. ${ }^{36,37}$ In adipocytes, AMPK mediates leptin inhibition of lipolysis and decreases the release of FFAs, promoting accumulation of TGs in fat cells ${ }^{37}$.

As shown in Figure 1A, binding of leptin to its receptor also stimulates the JAK/STAT system to control metabolism at the transcriptional level.

\section{Hormone Resistances Cause Vascular Damage and Hypertension}

Resistance to insulin and leptin typically results in elevated plasma glucose, FFAs and TGs. ${ }^{4-9}$ Among the consequences of hyperglycemia is the non-enzymatic reaction of glucose with protein amino groups ${ }^{15,}{ }^{16}$. Hemoglobin $\mathrm{A} 1 \mathrm{C}$ assays monitor this reaction with hemoglobin to assess chronic hyperglycemia, but similar glycation reactions occur with amino groups on many proteins. ${ }^{15,16}$ Diabetic complications such as hypertension, retinal damage and blindness, decreased peripheral circulation and infections, heart and kidney disease can be attributed, in part, to protein glycation., ${ }^{4,9}$

Dyslipidemia refers to a poor lipid profile, involving high TGs, high total cholesterol, and a low HDL-toLDL ratio. ${ }^{4-9}$ This condition is typically found in obese patients with insulin and leptin resistance, and frequently results in lipotoxicity and atherosclerosis (discussed below). Elevated FFAs contribute significantly to lipotoxicity and athero-sclerosis, but their levels are seldom measured. Leptin resistance also affects vascular remodeling, as suggested by the development of ventricular hypertrophy by leptin deficient or resistant mice. $^{28,30,33}$

FFAs, Ceramide, Bcl-2, and Apoptosis

As illustrated in Figure 1, serum FFAs and leptin binding affect production of transcription factors (designated PPAR- $\alpha$ and PPAR- $\gamma$ ) and alter lipid metabolism in non-adipose cells. When FFA levels are low, the catabolic processes of $\beta$-oxidation dominate and a minimal lipid pool exists for immediate energy requirements. Leptin resistance and high FFA levels cause TG synthesis to dominate the lipid buffering cycle and ectopic fat begins to accumulate (figure 1). Unger and coworkers suggest that among leptin's primary role is the control of ectopic fat deposition. ${ }^{39}$

Ceramides are a class of compounds that play an important role in lipotoxicity and initiation of apoptosis (programmed cell death). ${ }^{9,}{ }^{11}$ Sphingosine is first derived from a reaction of a fatty acid, palmitate, and an amino acid, serine. ${ }^{911,12}$ The sphingosine backbone has various 
groups added (similar to the additions made to the glycerol backbone in phospholipids) to form the ceramides. ${ }^{12}$

serine + palmitate $\rightarrow$ sphingosine $\rightarrow$ ceramide $\rightarrow$ induction of iNOS $\rightarrow \uparrow \mathrm{NO} \rightarrow$ apoptosis

The above sequence shows ceramide compounds activating the inducible nitric oxide synthase (iNOS), which produces toxic levels of $\mathrm{NO}$ and promotes apoptosis. ${ }^{9,11,12}$

The Bcl-2 gene family helps suppress apoptosis, but exposure of pancreatic cells to high FFA levels down regulates $\mathrm{Bcl}-2 \mathrm{~m}$ resulting in rapid cell death. ${ }^{9,}{ }^{12}$ Leptin reverses this downregulation and increases cell survival. In leptin-resistant $\mathrm{fa} / \mathrm{fa}$ rodents (lacking leptin receptors), leptin cannot reverse Bcl-2 suppression and islet cells still die quickly. Reinsertion of a functional receptor gene "cures" the deficiency, enabling leptin to block FFA-related apoptosis so that cells achieve a normal life span. ${ }^{9}{ }^{11-13}$ Leptin prevents both ceramiderelated cell damage and apoptotic effects resulting from high FFAs. Leptin resistance, common in obese patients, allows for these forms of lipotoxicity. ${ }^{9,11-13}$

\section{Inflammation \& High LDLs Promote Atherosclerosis}

Mature VAT adipocytes secrete a wide array of proinflammatory adipokines (cytokines secreted by fat cells), which promote inflammation, recruit macrophages, and stimulate smooth muscle and fibroblast expansion. Proinflammatory adipokines and cytokines include: CRP, $\alpha$-TNF, IL-1, IL-6, IL-8, IL-10, resistin, and two chemokines. ${ }^{28-30}$

$\alpha$-TNF is one of the primary inflammatory and lipotoxic factors stimulating the acute phase response, including secretion of CRP and other proinflammatory factors. $^{28,} 29$ In conjunction with IL- $6, \alpha$-TNF also stimulates phagocytosis, promotes adhesion of WBCs to endothelial cells, and is a potent chemoattractant for neutrophils. $\alpha$-TNF also contributes to insulin resistance by inhibiting insulin receptor signaling pathways. ${ }^{28-30}$
RT-PCR experiments (using reverse transcriptase to copy mRNAs, followed by PCR amplification) demonstrated CRP synthesis by adipocytes. ${ }^{39}$ CRP is an opsonin and marker of inflammation that correlates with increased cardiac risk. Resistin is an adipokine that promotes insulin resistance, expression of adhesion molecules on human endothelial cells, and increased CVD risk. ${ }^{40}$ Angiotensinogen and ACE (angiotensin converting enzyme) are also secreted by adipocytes and promote hypertension, another characteristic of MSX. ${ }^{37}$ Together, these secretory products promote what Ross called a "hyperresponsive healing" process resulting in destruction of vascular tissue, fibrosis, necrosis, and calcification that may ultimately rupture and cause thrombosis. $^{21}$

Plaque formation and the resulting atherosclerosis are well documented consequences of dyslipidemia. ${ }^{11,} 12$ Oxidized LDLs are engulfed by foam cells, which intercalate between the endothelial and smooth muscle layers of the arteries, contributing to plaque formation. ${ }^{11,12,41}$

\section{Adiponectin (ADN) is Anti-inflammatory and Anti- atherogenic}

As illustrated by Figure 4, $\mathrm{ADN}$ is an anti-inflammatory adipokine that help protect against atherosclerosis by inhibiting endothelial adhesions, recruitment of macrophages, endothelial dysfunction, inflammation, and plaque formation. ${ }^{41}$ Ouchi found that $\mathrm{ADN}$ is lower and CRP is higher in patients with coronary artery disease. ${ }^{40}$ Similarly, ADN-deficient mice had higher CRP levels than mice with normal ADN levels. ${ }^{40}$

ADN reduces expression of vascular adhesion molecules and inhibits adhesion of monocytes to endothelial cells. $^{21,33,41} \mathrm{ADN}$ also inhibits expression of "LDLscavenger receptors" on macrophages, reducing LDL uptake and producing fewer plaque-forming foam cells. $^{21,33,41}$ Excessive endothelial injuries and vascular remodeling were also seen in $\mathrm{ADN}$ deficient mice. Adiponectin affects the AMPK system by altering uptake, metabolism, and storage of both lipids and glucose. $^{27,37}$ 


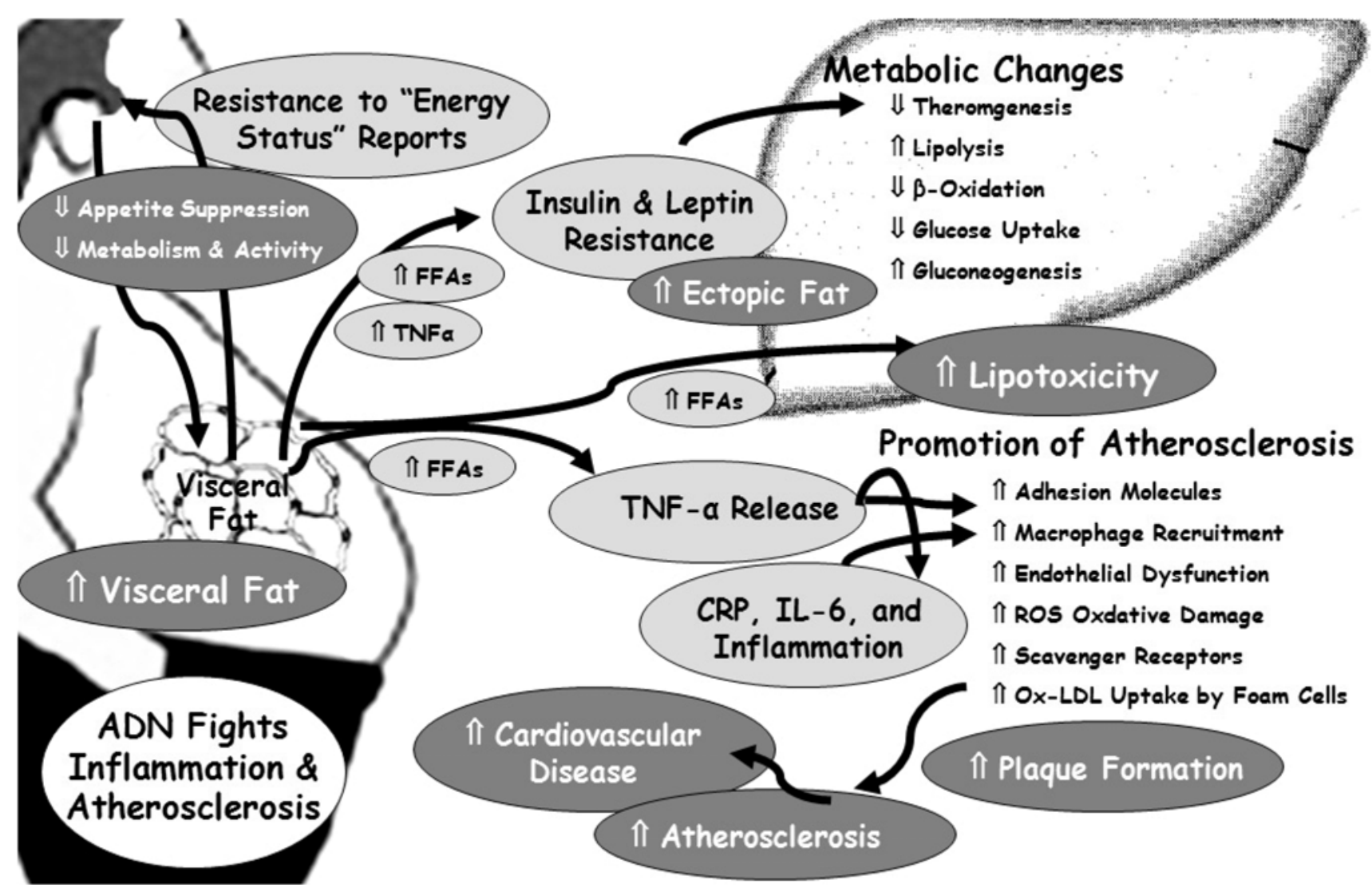

Figure 4: Summary of the Pathophysiology of Metabolic Syndrome

Metabolic syndrome develops as failed hormonal feedback (resistance to leptin and insulin) results in deposition of ectopic and visceral fat, release of adipokines tumor necrosis factor (TNF- $\alpha$ ), C-reactive protein (CRP), interleukin 6 (IL-6) and elevated free fatty acid (FFA) levels. These lead to metabolic dysregulation, lipotoxicity, inflammation, and promotion of changes resulting in atherosclerosis and heart disease. Adiponectin $(\mathrm{ADN})$ counteracts many of these proinflammatory effects and fights atherosclerosis.

\section{ADN Promotes Insulin Sensitivity}

Plasma ADN promotes insulin sensitivity and increased $\beta$-oxidation, and its level is inversely related to levels of VAT. ${ }^{4,5,41,42}$ Mice lacking ADN developed marked hyperglycemia and insulin resistance, even without obesity. Both conditions were reversed with administration of $\mathrm{ADN} .{ }^{33} \mathrm{ADN}$ counters many of the negative outcomes of obesity and MSX, including inflammation, atherosclerosis, hyperglycemia, and insulin resistance.

Some obese patients inherit lower ADN levels and become leptin resistant, have increased VAT, and become insulin resistant. Japanese families with histories of DM2 had single nucleotide polymorphisms (SNPs) in their $\mathrm{ADN}$ gene, resulting in lower ADN levels (10.4 $\mu \mathrm{g} / \mathrm{mL}$, compared to the normal $16.6 \mu \mathrm{g} / \mathrm{mL}){ }^{40,} 41,45$
Similarly, the Pima Indians have a high prevalence of obesity, with lower ADN levels, insulin resistance, DM2, ischemia, hypertension, and CVD. ${ }^{33,40,41,43}$ In one study of nine patients with inherited low ADN levels, all nine had hyperglycemia, eight of the patients had hypertension or hyperlipidemia, and six had already developed CVD. ${ }^{41,44}$

\section{Metabolic Syndrome's Overall Effects}

Several factors, relating to obesity and MSX, have been shown to affect an individual's risk of cardiovascular disease. Among the most powerful of these factors are leptin and ADN. Leptin exerts its influence primarily during the development of obesity, signaling the hypothalamus concerning "adiposity," or the status of energy reserves. Adequate reserves (moderate leptin 
levels) result in appetite suppression and thermogenesis, eliminating excess calories while preventing abdominal fat deposition. Chronic overindulgence results in leptin resistance, increased appetite, deposition of abdominal fat, and the development of obesity. ADN retards the many negative consequences of obesity and MSX, such as chronic inflammation and development of atherosclerosis.

Two common metabolites central to the development of MSX are glucose and FFAs. The devastating effects of chronic hyperglycemia are known to cause many sequelae of diabetes. The toxic effects of elevated FFAs have recently become appreciated as major contributors to the development of MSX, lipotoxicity, and CVD.

The most devastating consequences of abdominal obesity include: 1) resistance to insulin and leptin, 2) dyslipidemia related to increased VAT, 3) chronic inflammation leading to atherosclerosis, and 4) lipotoxic damage to tissues and vasculature. Together, these result in a dramatically increased risk of CVD.

\section{REFERENCES}

1. Reaven GM. Role of insulin resistance in human disease. Diabetes 1988; 37:1595-607.

2. Reaven GM. Metabolic syndrome; pathophysiology and implications for management of cardiovascular disease. Circulation 2002;106:286-88.

3. Kaplan NM. The deadly quartet: upper body obesity, glucose intolerance, hypertriglyceridemia, and hypertension. Arch Intern Med 1989;149:1514-20.

4. Hansen BC. The metabolic syndrome X. Ann NY Acad Sci 1999; 892: 1-21.

5. Miranda PJ, DeFronzo RA, Califf RM, and others. Metabolic syndrome: definition, pathophysiology, and mechanisms. Am Heart J 2005;149:33-45.

6. Vega GL. Obesity, the metabolic syndrome, and cardiovascular disease. Am Heart J 2001;142:1108-16.

7. Flier JS, Flier EM. What fuels fat? Sci Amer 2007; 297: 72-81.

8. Kahn BB, Flier JS. Obesity and insulin resistance. J Clin Invest 2000;106:473-81.

9. Unger, RH, Lipotoxic Diseases. Ann Rev Med 2002; 53:31936.

10. Zimmett P, Thomas CR, Genotype, obesity and cardiovascular disease-has technical and social advancement outstripped evolution? J Intern Med 2003; 254: 114-125J.
11. Unger RH. Hyperleptinemia: protecting the heart from lipid overload. Hypertension 2005;45:1031-4.

12. Unger RH, Longevity, lipotoxicity and leptin: the adipocyte defense against feasting and famine. Biochimie 2005; 87: 5764.

13. Unger RH, Weapons of lean body mass destruction: the role of ectopic lipids in the metabolic syndrome. Endocrinol 2003; 144: 5159-65.

14. The World Health Organization Report. 2002 Reducing Risks, Promoting Healthy Life. Geneva, Switzerland: World Health Organization.

15. Hartz AJ, Rupley Jr DC, Kalkhoff RK, and others. Relationship of obesity to diabetes: influence of obesity level and body fat distribution. Prev Med. 1983; 12:351-7.

16. Lieberman M, Marks AD. Marks' Basic Medical Biochemistry, 3rd Edition, 2009, Lippincott, Williams, \& Williams, Philadelphia.

17. Bouchard C. Genetics of human obesity: recent results from linkage studies. J Nutr 1997; 127: 1887S-90S.

18. Montague C, Farooqi I, Whitehead J. Congenital leptin deficiency is associated with severe early-onset obesity in humans. Nature 1997;387: 903-8.

19. Lyon HN, Hirschhorn JN. Genetics of common forms of obesity: a brief overview. Am J Clin Nutr 2005; 82(suppl): 215S-7S.

20. O'Rahilly S, Farooqi IS. Genetics of obesity. Phil Trans R Soc B 2006; 361, 1095-105.

21. Ross R. Atherosclerosis: an inflammatory disease. N Eng. J Med 1999;340:115-26.

22. Gade, W, Gade, J, Collins,M, and others. Failures of Feedback: Rush Hour Along the Highway to Obesity. Clin. Lab. Sci. 2009; 23(1);39.

23. Grundy SM, Brewer HB, Cleeman JI, and others. Definition of metabolic syndrome: report of the National Heart, Lung, and Blood Institute/American Heart Association conference on scientific issues related to definition. Circulation 2004;109:433-8.

24. Dallman M F, La Fleur S, Pecoraro N C. and others. Minireview: glucocorticoids-food intake, abdominal obesity, and wealthy nations in 2004. Endocrin. 2004; 145:2633-8.

25. Stewart PM, Boulton A, Kumar S. Cortisol metabolism in human obesity: impaired cortisone-cortisol conversion in subjects with central adiposity. J Clin Endocrinol Metab 1999: 84; 1022-7.

26. Macfarlane DP, Forbes S, Walker BR. Glucocorticoids and fatty acid metabolism in humans: fueling fat redistribution in the metabolic syndrome. J Endocrin 2008; 197: 189-204. 
27. Collins S, Kuhn C, Petro A, and others. Role of leptin in fat regulation. Nature 1996;380:677-9.

28. Friedman J, Halaas J. Leptin and the regulation of body weight in mammals. Nature 1998;395:763-70.

29. Angulo P. Nonalcoholic fatty liver disease. N Engl J Med 2002;346:1221-31.

30. Marchesini G, Brizi G, Bianchi G. Nonalcoholic fatty liver disease: a feature of the metabolic syndrome. Diabetes 2001; 50: 1844-50.

31. Huang W, Dedousis N, O’Doherty RM. Hepatic steatosis and plasma dyslipidemia induced by a high-sucrose diet are corrected by an acute leptin infusion. J Appl Physiol 2007; 102: 2260-5.

32. Kawai T, Kazuo TI, Ohwada YM, and others. Hereditary postprandial hypertriglyceridemic rabbit exhibits insulin resistance and central obesity: A novel model of metabolic syndrome. Arter Thromb Vasc Biol 2006; 26:2752-7.

33. Matsuzawa Y, Funahashi T, Kihara S. Adiponectin and metabolic syndrome. Arterioscler Thromb Vasc Biol 2004;24:29-33.

34. Barouch LA, Berkowitz DE, Harrison RW, et al. Disruption of leptin signaling contributes to cardiac hypertrophy independently of body weight in mice. Circulation 2003;108:754-9.

35. Franckhauser $S$, Munoz $S$, Pujol A. Increased fatty acid reesterification by PEPCK overexpression in adipose tissue leads to obesity without insulin resistance. Diabetes 2002; 51 : 62430.

36. Ruderman NB, Saha AK, Kraegen AW. Minireview: malonyl coA, AMP-activated protein kinase, and adiposity. Endocrinology 2003; 144: 5166-71.
37. Andersson U, Filipsson K, Abbott CR, AMP-activated protein kinase plays a role in the control of food intake. J Biol Chem 2004; 279: 12005-8.

38. Kim SF, Huang AS, Snowman AM, and others. Antipsychotic drug-induced weight gain mediated by histamine $\mathrm{H} 1$ receptorlinked activation of hypothalamic AMP-kinase. Proc Natl Acad Sci 2007; 104: 3456-9.

39. Unger RH, Zhou YT, Orci L. Regulation of fatty acid homeostasis in cells: novel role of leptin. Proc Natl Acad Sci 1999; 96: 2327-32.

40. Ouchi N, Kihara S, Funahashi T, and others. Reciprocal association of C-reactive protein with adiponectin in blood stream and adipose tissue. Circulation 2003;107: 671-4.

41. Szmitko PE, Teoh H, Stewart DJ, and others. Adiponectin and cardiovascular disease: state of the art? Am J Physiol Heart Circ Physiol 2007; 292: H1655-63.

42. Frankel DS, Vasan RS, D’Agostino RD. Resistin, adiponectin, and risk of heart failure: the Framingham offspring study. J Am Coll Cardiol 2009; 53: 754-62

43. Stefan N, Vozarova B, Funahashi T, and others. Plasma adiponectin concentration is associated with skeletal muscle insulin receptor tyrosine phosphorylation, and low plasma concentration precedes a decrease in whole body insulin sensitivity in humans. Diabetes 2002;51:1884-8.

44. Hotta K, Funahashi T, Arita Y, and others. Plasma concentrations of a novel, adipose-specific protein, adiponectin in type 2 diabetic patients. Arterioscler Thromb Vasc Biol 2000; 20:1595-9.

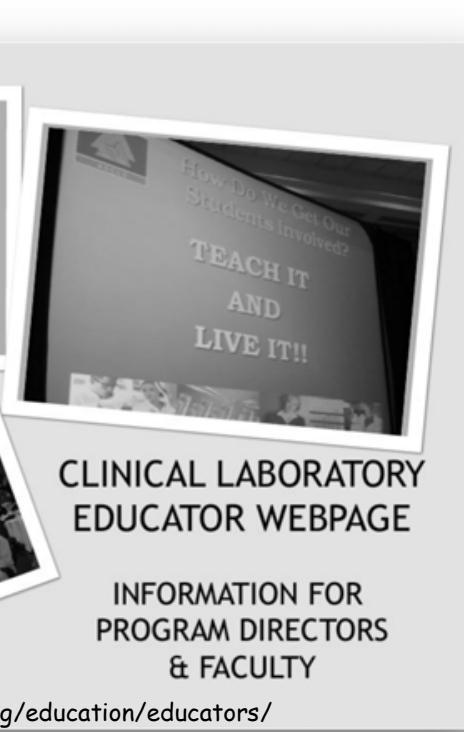

VOL 23, NO 1 WINTER 2010 CLINICAL LABORATORY SCIENCE 61 